\title{
Sonochemical degradation of azithromycin in aqueous solution
}

\author{
Atiyeh Yazdani ${ }^{1}$, Mohammad Hossein Sayadi ${ }^{*}$ \\ ${ }^{1}$ Department of Environmental Sciences, Faculty of Natural Resources and Environment, University of Birjand, Birjand, Iran
}

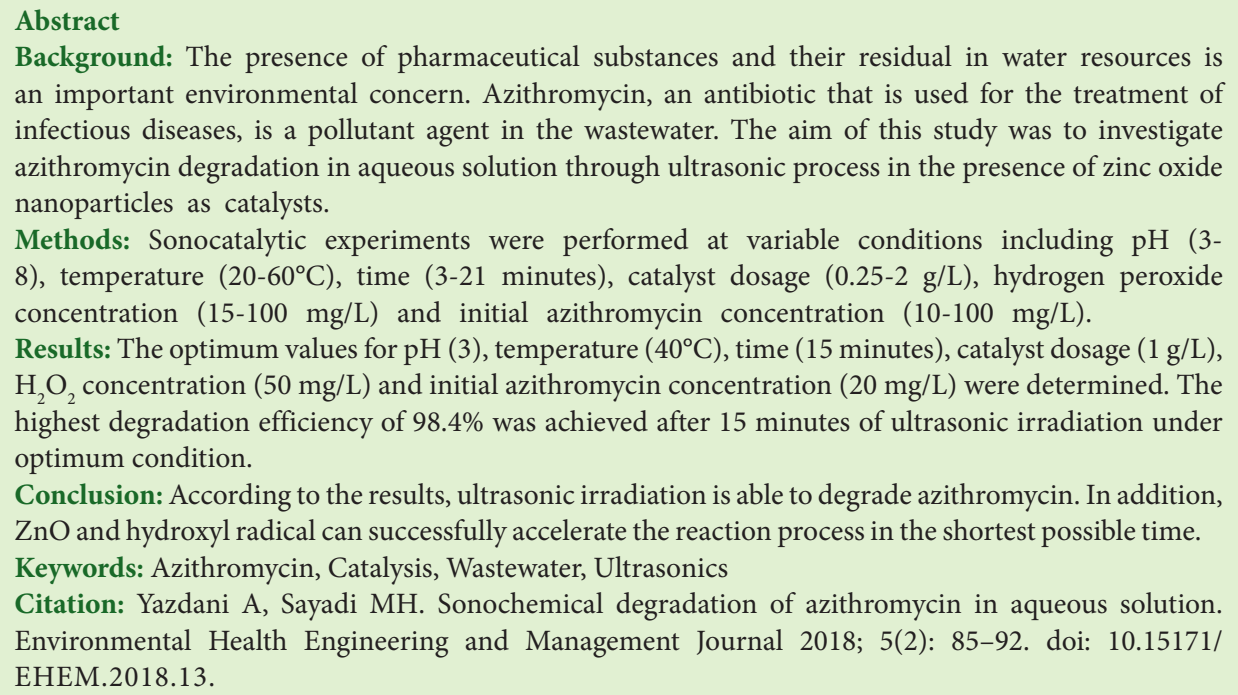

Article History:

Received: 9 March 2018 Accepted: 21 May 2018

ePublished: 15 June 2018

\section{Introduction}

One of the important pollutants in the environment is drug substance. More than $90 \%$ of the drugs are disposed and discharged into urban wastewater, and since the conventional treatment system is not efficient to remove these materials, hence, they enter the environment as water resources (1-3). Moreover, pharmacies and unprocessed drugs are also the main sources of drug entry into the environment. Antibiotics account for about 15\% of total drug usage and are considered as one of the major pollutants of aquatic systems such as wastewater treatment plants besides surface, drinking and ground waters $(4,5)$. The presence of antibiotics and pharmaceuticals in water has become a significant concern in recent years.

azithromycin as one of the most important macrolide antibiotics in medicine, is used to treat infection in humans and animals (6). Usually, these substances are not removed in the usual primary and secondary purification processes of a refinery, therefore, they can enter into the water supplies $(7,8)$. The presence of these compounds in the aquatic environment can lead to toxicity, development of antibiotic-resistant strains, and subsequently, treat the human health and ecosystem function. Therefore, an efficient purification system is necessary to remove these compounds (9). In recent years, the chemical oxidation processes such as ozonation, oxidation, and photolysis have been introduced to remove such contaminants. Baran et al studied the removal of four antibiotics (sulfadiazine, sulfamethoxazole, sulfathiazole and sulfacetamide) by photocatalytic method and reported that the produced intermediates had less toxicity than the primary compounds (10). Uslu and Balcioglu reported almost total removal of antibiotics i.e. oxytetracycline and sulfamethazine, but the main concern with the ozonation process is the possibility of converting toxic compounds into undegradable compounds (11). The ultrasonic method is a sample of advanced oxidation processes (AOPs) that decomposes and degrades organic pollutants. The ultrasonic method has some unique benefits such as non-use of chemicals, ease of use and high efficiency compared to other technologies (12). Recently, the use of ultrasonic method alone or combined with other materials or processes has been considered as the most efficient method. Using the ultrasonic process alone will require a long time and high energy consumption to remove pollutants. Therefore, in order to reduce the time 
and energy consumption, semiconductor nanoparticles such as titanium dioxide ( $\mathrm{TiO} 2)$, zinc oxide $(\mathrm{ZnO})$ and copper oxide $(\mathrm{Cu} 2 \mathrm{O})$ are used (13-15). The ultrasonic process using catalysts, is a relatively new process in water treatment compared to the other AOPs that can make antibiotics less toxic or less toxic byproducts, therefore, it is used as an effective method for the decomposition of pollutants with low biodegradability, such as antibiotics (16). Villaroel et al examined ultrasonic degradation of acetaminophen, and reported that ultrasound has shown remarkable ability to degrade acetaminophen, and in comparison to other AOPs (Fenton, photo-Fenton, UV/ $\mathrm{H}_{2} \mathrm{O}_{2}$ ), it showed no harmful effects (17). Ultrasonic method can improve the catalytic oxidation process by activating the catalyst surface. The combination of a catalyst with ultrasound has a synergistic effect on the pollutant degradation. In addition, the ultrasonic process consumes considerable energy and time, which makes it a costly affair. To solve this problem, catalysts are added to the ultrasonic reaction system to reduce the activation energy and accelerate the response (18). Hartmann et al showed that the degradation of diclofenac in water by ultrasonic process in the presence of a catalyst is a useful method for the degradation of pharmaceutical compounds in water. Using this combined method in the presence of titanium dioxide $\left(\mathrm{TiO}_{2}\right), 84 \%$ of diclofenac was removed from water in 30 minutes (19). Zinc oxide nanoparticles are cheap and its catalytic properties will be appeared if the input energy be more than the energy required for its stimulation (20). Accordingly, the ultrasonic process with $\mathrm{ZnO}$ as a catalyst, can be used in the process of sonocatalysis (ultrasonically assisted catalysis) to purify water resources. This catalyst is a non-toxic, corrosion resistant and strong oxidizer (21). The purpose of this study was to investigate the azithromycin degradation through ultrasonic process in water using a $\mathrm{ZnO}$ catalyst considering the effect of different parameters such as $\mathrm{pH}$, azithromycin concentration, catalyst concentration, time and temperature in order to find the optimal values.

\section{Materials and Methods}

Materials

Azithromycin powder was prepared by Sigma (St. Louis, MO, USA), $\mathrm{ZnO}$ nanoparticles as a catalyst, with size ranging from 20 to $60 \mathrm{~nm}$ and purity of $99.5 \%$, was taken from Rouinsazan company, Iran. The SEM of $\mathrm{ZnO}$ nanoparticles is shown in Figure 1. Methanol and $\mathrm{H}_{2} \mathrm{O}_{2}$ were purchased from Merck (Darmstadt, Germany). In addition, $\mathrm{pH}$ meter (Istek, 915PDC), ultrasonic device (PARSONIC 7500 S, 220 VAC, Iran), UV-Vis spectrophotometer (Shimadzu Corporation, Japan), were also used.

\section{Preparation of azithromycin solution}

Azithromycin is an erythromycin derivative that its chemical formula is $\mathrm{C}_{38} \mathrm{H}_{72} \mathrm{~N}_{2} \mathrm{O}_{12}$. Its solvent is generally methanol. Figure 2 shows its molecular structure. The concentrations of azithromycin solution were determined by dissolving different amounts of azithromycin powder in $100 \mathrm{~mL}$ of methanol $(20,40,70$, and $100 \mathrm{mg} / \mathrm{L})$. The solution was adjusted at various $\mathrm{pHs}$ $(3,4,5,6,7$ and 8) using $\mathrm{HCl}$ and $0.01 \mathrm{M} \mathrm{NaOH}$. At each stage, different parameters such as ultrasonic time (3, 6, $12,15,18$ and 21 minutes), temperature $(20,30,40,50$ and $\left.60^{\circ} \mathrm{C}\right)$, catalyst concentration $(0,0.25,0.5,0.75,1$, and $2 \mathrm{~g} / \mathrm{L})$ and $\mathrm{H}_{2} \mathrm{O}_{2}$ at different concentration $(15,20,40,50$, 75 , and $100 \mathrm{mg} / \mathrm{L}$ ) were tested using an ultrasonic device at a frequency of $35 \mathrm{kHz}$. Samples were taken at selected times, filtered through Whatman no. 0.45 filter paper and prepared for reading.

\section{Analysis}

To determine the concentration of azithromycin, UV analysis was performed by UV-Vis spectrophotometer at a wavelength of $547 \mathrm{~nm}$, and the optimal value of each parameter and removal rate were determined.

\section{Results}

Effect of $\mathrm{pH}$ solution on azithromycin degradation Several studies have shown that $\mathrm{pH}$ of the solution plays an important role in the ultrasonic removal of organic pollutants. This can be due to its effects on the distribution of electric charge on the catalyst surface and oxidation potential. Studies have also shown that $\mathrm{pH}$ has a significant effect on the degradation and removal of antibiotics. In

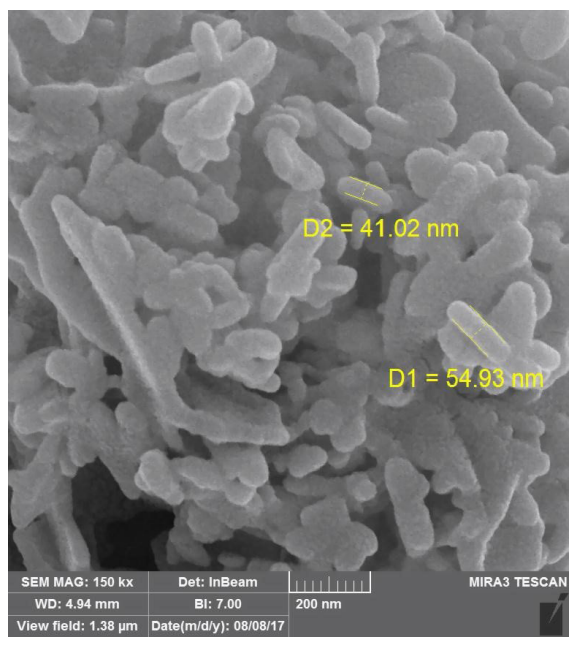

Figure 1. SEM of $\mathrm{ZnO}$ nanoparticles.

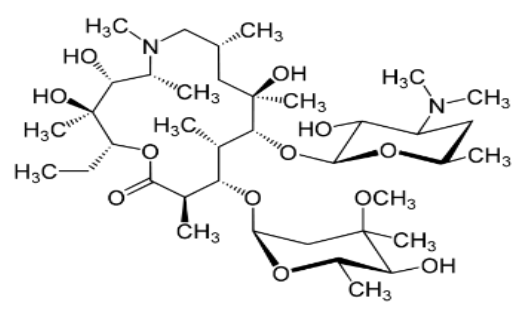

Figure 2. Molecular structure of azithromycin. 
this study, the $\mathrm{pH}$ values from 3 to 8 were tested under test conditions (concentration of azithromycin $=40 \mathrm{mg} / \mathrm{L}$, catalyst concentration $=1 \mathrm{~g} / \mathrm{L}$ and temperature $=30^{\circ} \mathrm{C}$ ) for 15 minutes in the presence of $\mathrm{ZnO}$ catalyst (Figure 3 ).

Effect of reaction temperature on azithromycin degradation To determine the effect of temperature on azithromycin degradation, experiments were performed at 5 different temperatures ranging from 20 to $60^{\circ} \mathrm{C}$ and constant values of other parameters (contaminant concentration $=40$ $\mathrm{mg} / \mathrm{L}, \mathrm{ZnO}$ catalyst concentration $=1 \mathrm{~g} / \mathrm{L}$ and time $=15$ minutes) and optimized $\mathrm{pH}$ value. As shown in Figure 4, the removal rate has increased with increasing temperature, especially from 20 to $40^{\circ} \mathrm{C}$. But at temperatures from 40 to $60^{\circ} \mathrm{C}$, there was a steady decrease in the removal rate.

Effect of reaction time on azithromycin degradation level To investigate the effect of reaction time on the azithromycin degradation, under optimized conditions $\left(\mathrm{pH}=3\right.$ and temperature $=40^{\circ} \mathrm{C}$ ) and constant parameters (azithromycin concentration $=40 \mathrm{mg} / \mathrm{L}$, and catalyst concentration $=1 \mathrm{~g} / \mathrm{L}$ ), sampling was carried out at intervals of 3 to 21 minutes after experiment using low-frequency ultrasound $(35 \mathrm{kHz})$. Figure 5 shows the removal rate of azithromycin over time. The results demonstrated that there was a significant increase in the

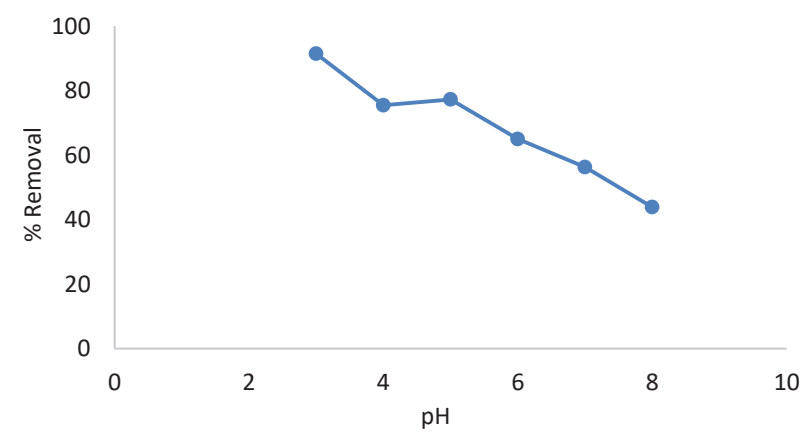

Figure 3. Effect of $\mathrm{pH}$ on azithromycin degradation at azithromycin concentration $=40 \mathrm{mg} / \mathrm{L}$, catalyst concentration $=1$ $\mathrm{g} / \mathrm{L}$, temperature $=30^{\circ} \mathrm{C}$, and time $=15 \mathrm{~min}$.

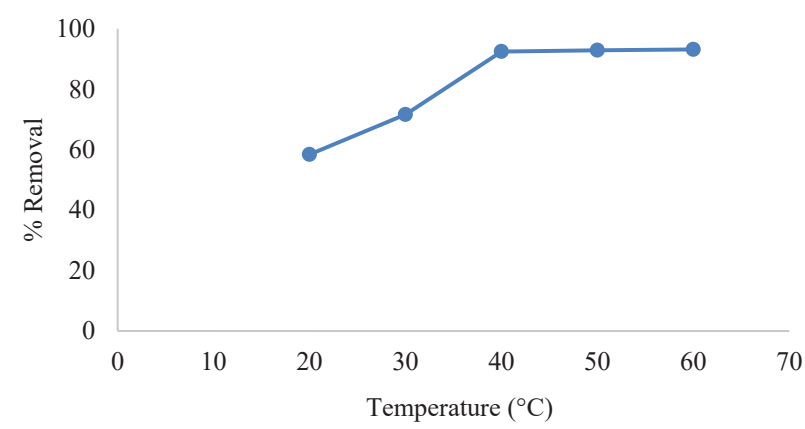

Figure 4. Effect of temperature on azithromycin degradation at contaminant concentration $=40 \mathrm{mg} / \mathrm{L}$, catalyst concentration $=1$ $\mathrm{g} / \mathrm{L}$, time=15 $\mathrm{min}$, and $\mathrm{pH}=3$. percentage of removal in the first 15 minutes, then, no significant change was observed.

Effect of zinc oxide catalyst concentration on azithromycin degradation

Degradation of azithromycin in water was performed in the presence of $\mathrm{ZnO}$ catalyst. The presence of catalysts accelerates the degradation of pollutants in the reaction. In a solution of $40 \mathrm{mg} / \mathrm{L}$ azithromycin at $\mathrm{pH}=3$ and $40^{\circ} \mathrm{C}$, the optimum catalyst level was obtained by ultrasonication of $1 \mathrm{~g} / \mathrm{L} \mathrm{ZnO}$ catalyst after $15 \mathrm{~min}$ of degradation. According to Figure 6, the increase in catalyst content in the solution from 0.25 to $2 \mathrm{~g} / \mathrm{L}$ leads to an increase in the removal efficiency of azithromycin.

Effect of $\mathrm{H}_{2} \mathrm{O}_{2}$ on azithromycin degradation rate According to researchers, the addition of an oxidizing agent, such as $\mathrm{H}_{2} \mathrm{O}_{2}$, as a hydroxyl radical producer, significantly increases the efficiency of organic pollutant degradation in AOPs. To maximize efficiency, $\mathrm{H}_{2} \mathrm{O}_{2}$ concentration should be selected according to the type and concentration of pollutants. To investigate the effect

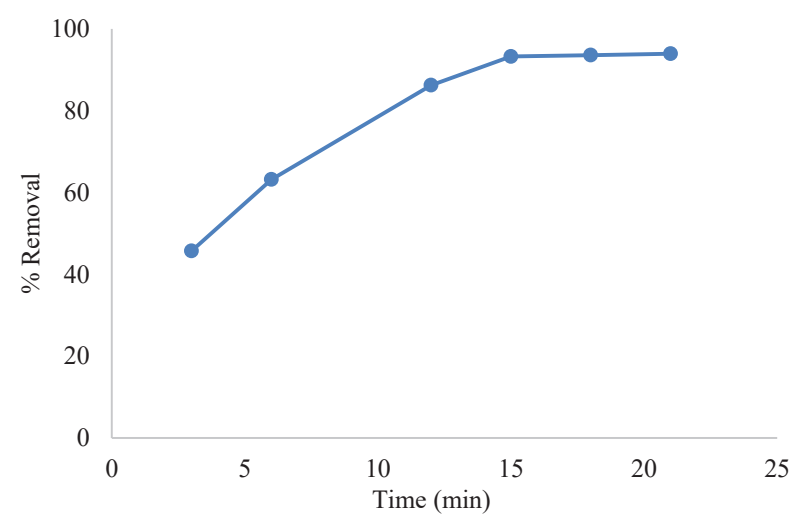

Figure 5. Effect of time on azithromycin degradation level at $\mathrm{pH}=3$, temperature $=40^{\circ} \mathrm{C}$, azithromycin concentration $=40 \mathrm{mg} / \mathrm{L}$, and catalyst concentration $=1 \mathrm{~g} / \mathrm{L}$.

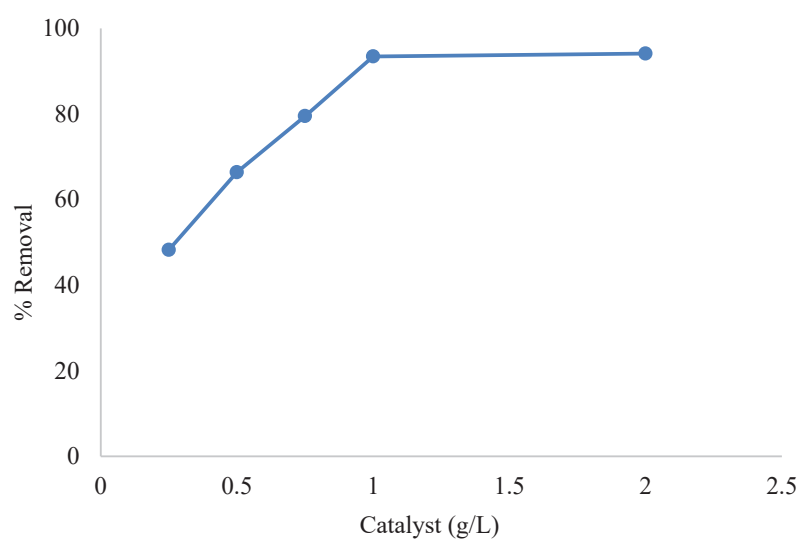

Figure 6. Effect of catalyst concentration on azithromycin degradation at $\mathrm{pH}=3$, temperature $=40^{\circ} \mathrm{C}$, azithromycin concentrations $=40 \mathrm{mg} / \mathrm{L}$, and time $=15 \mathrm{~min}$. 
of $\mathrm{H}_{2} \mathrm{O}_{2}$ at different concentrations $(15,20,40,50,75$, and $100 \mathrm{mg} / \mathrm{L}$ ), azithromycin concentration $=40 \mathrm{mg} / \mathrm{L}, \mathrm{ZnO}$ catalyst concentration $=1 \mathrm{~g} / \mathrm{L}$, temperature $=40^{\circ} \mathrm{C}, \mathrm{pH}=3$ in 15 minutes are essential. The percentage of azithromycin removal at different concentrations of $\mathrm{H}_{2} \mathrm{O}_{2}$ is shown in Figure 7. The results reveal that the use of $\mathrm{H}_{2} \mathrm{O}_{2}$ with a catalyst has a direct effect on the azithromycin removal rate. So that the sonocatalysts solely increased from $81.78 \%$ to $98.4 \%$ at $40 \mathrm{mg} / \mathrm{L}$ azithromycin in a 15 -minute period using $50 \mathrm{mg} / \mathrm{L} \mathrm{H}_{2} \mathrm{O}_{2}$ (optimal amount).

Effect of azithromycin concentration on degradation rate By optimizing the effective parameters of degradation efficiency, the azithromycin concentration that had the highest degradation efficiency in optimal conditions, was selected. For this purpose, different concentrations $(10,20,40,70$, and $100 \mathrm{mg} / \mathrm{L})$ of azithromycin solution were prepared under optimal conditions $(\mathrm{pH}=3$, temperature $=40^{\circ} \mathrm{C}$, catalyst concentration $=1 \mathrm{~g} / \mathrm{L}$ and $\mathrm{H}_{2} \mathrm{O}_{2}$ concentration $=50 \mathrm{mg} / \mathrm{L}$ ) was sonolyzed for 15 minutes. Figure 8 shows the azithromycin degradation percentage at 5 different concentrations. Based on the results, the decrease in azithromycin concentration increased the removal efficiency. Decreasing contaminant concentration had the same effect as increasing the catalyst concentration. By decreasing azithromycin concentration from $100 \mathrm{mg} / \mathrm{L}$ to $10 \mathrm{mg} / \mathrm{L}$, the degradation rate increased from $30 \%$ to $99.8 \%$ after 15 minutes.

\section{Discussion}

According to the results obtained in Figure 2, with increasing $\mathrm{pH}$, the degradation process of azithromycin decreased and acidic conditions helped degrade azithromycin. As $\mathrm{pH}$ decreased due to the reduction of hydroxyl radicals, the efficiency of the process also decreased. The effect of acidic environment to increase the efficiency can be shown as follows:

$2 \mathrm{HO}_{20} \rightarrow \mathrm{O}_{2}^{\circ}+\mathrm{H}_{2} \mathrm{O}_{2}$

$\mathrm{H}_{2} \mathrm{O}_{2}+\mathrm{O}_{2}^{\circ} \rightarrow \mathrm{OH}^{0}+\mathrm{OH}^{-}+\mathrm{O}_{2}$

$\mathrm{e}^{-}+\mathrm{O}_{2} \rightarrow \mathrm{O}_{2}^{0-}$

$\mathrm{O}_{2}^{0-}+\mathrm{H}^{+} \longrightarrow 2 \mathrm{HO}_{2}^{0}$

The basis of AOPs is hydroxyl radical production. But at higher $\mathrm{pHs}, \mathrm{H}_{2} \mathrm{O}_{2}$ decomposes quickly and reduces radical formation $(7,22)$. The effect of $\mathrm{pH}$ on azithromycin degradation depends on the structure and properties of the agent and also on its PKa value. The $\mathrm{pKa}$ value of azithromycin is 8.74 . Accordingly, in acidic solutions, it will usually be molecular. The molecular forms mainly directed to the liquid bubble transfer region, where there is a high $\mathrm{OH}$ concentration. According to the studies, the accumulation of catalyst particles in the acidic solution decreases, resulting in an increase in the effective surface of the catalyst, which leads to an increase in the sonocatalytic degradation in acidic conditions (15,23-25). Villaroel et al reported that in the degradation of acetaminophen by ultrasonic method, acidic medium $(\mathrm{pH}=3-5.6)$ is more

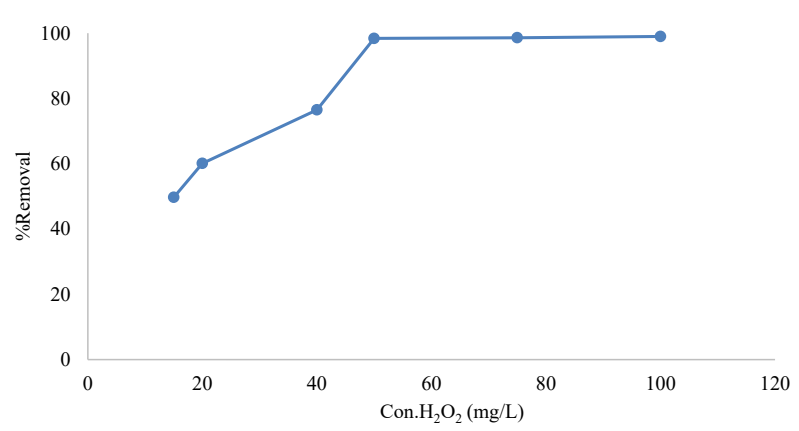

Figure 7. Effect of $\mathrm{H}_{2} \mathrm{O}_{2}$ on azithromycin removal percentage at azithromycin concentration $=40 \mathrm{mg} / \mathrm{L}, \mathrm{ZnO}$ catalyst=1 g/L, temperature $=40^{\circ} \mathrm{C}, \mathrm{pH}=3$, and time $=15 \mathrm{~min}$.

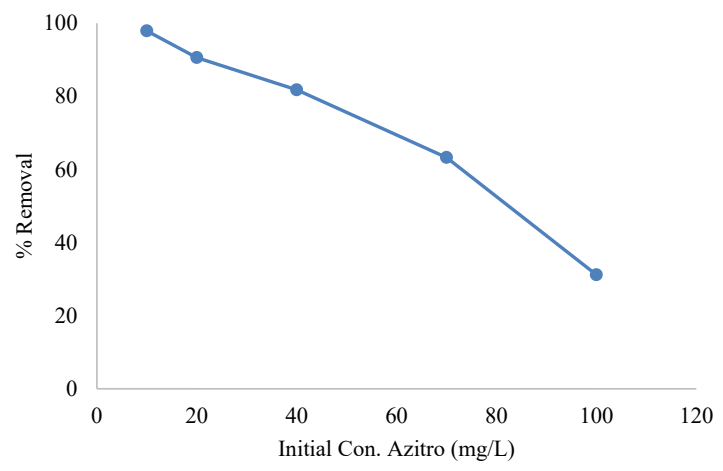

Figure 8. Effect of initial azithromycin concentration on removal percentage at $\mathrm{pH}=3$, temperature $=40^{\circ} \mathrm{C}$, catalyst concentration $=1$ $\mathrm{g} / \mathrm{L}, \mathrm{H} 2 \mathrm{O} 2$ concentration=50 $\mathrm{mg} / \mathrm{L}$, and time=15 $\mathrm{min}$.

suitable, thus acetaminophen (PKa 9.5) in acidic solutions in molecular form could has a higher degradation (17). Im et al also performed experiments at three different $\mathrm{pHs}$ $(3,7$ and 10) to investigate acetaminophen and naproxen degradation by oxidation processes (Sonocatalytic and Fenton). The results showed that when $\mathrm{pH}$ of the solution is low, the decomposition of compounds increases that in turn, increases the hydrophobic property of the acidic medium (25).

Ultrasonic tests are usually performed in the temperature control system to ensure that the isothermal conditions are maintained (26). The increase in temperature significantly increases the cavitation intensity and leads to azithromycin reduction. As the temperature increases, the vapor pressure increases and leads to the generation of more cavitation bubbles. Decomposition at a lower temperature reduces the concentration of radical hydroxyl, and subsequently decreases the degradation of contaminant (27-29). Braeutigam et al have shown that the rate constant depends on the reaction temperature, and the increase of the temperature has a positive effect on the reaction process. Reactions at temperatures below $25^{\circ} \mathrm{C}$ lead to the lower cavitation bubbles formation and concentration, and for substances with low solubility, the reaction is improved at higher temperatures (30). The removal rate of organic compounds is directly proportional 
to the temperature, because organic molecules migrate from the solution to the region where the hydroxyl radical concentration is high (31). Su et al investigated the sonocatalytic degradation of amoxicillin using sulfate radicals to determine the effect of temperature. They performed the experiments at a temperature ranging from 24 to $70^{\circ} \mathrm{C}$ and reported that the temperature increase, particularly from 24 to $40^{\circ} \mathrm{C}$, increased the degradation efficiency (32).

The reaction time is one of the variables that influences the performance of oxidation process. Optimizing time in the removal reactions will save the cost of utilization and energy consumption (33). Increased reaction time results in the production of hydroxyl radicals, further contact of these radicals with antibiotics, and ultimately, further degradation of azithromycin. Over time, active sites will change for antibiotic absorption and the number of products produced by the catalyst reaction increases in the aqueous medium, and subsequently the degradation efficiency increases $(34,35)$. The continuation of reaction for a long time leads to high energy consumption. Hence, achieving 93\% removal in 15 minutes will save energy (36).

The direct effect of increasing the catalyst on degradation efficiency is due to an increase in the level of access or active catalyst positions. As the amount of catalyst increases, the amount of hydroxyl radical produced also increases. In other words, the presence of catalysts in the sonocatalyst process leads to the production of additional nuclei, which increases the number of active bubbles and radicals $(37,38)$. In an ultrasonic process, the water is pyrolyzed in a portion of hydrogen radical, hydroxyl radical and oxygen radical, and then reacts with the pollutant. The reactions that occur are as follows $(39,40)$ : $\mathrm{H}_{2} \mathrm{O} \rightarrow \mathrm{OH}^{0}+\mathrm{H}^{0}$

$\mathrm{OH}^{0}+\mathrm{OH}^{0} \rightarrow \mathrm{H}_{2} \mathrm{O}_{2}$

$2 \mathrm{OH}^{0} \rightarrow \mathrm{H}_{2} \mathrm{O}+\mathrm{O}^{0}$

(Eq. 7)

$\mathrm{ZnO}+\mathrm{H}^{0} \longrightarrow \mathrm{Zn}^{2+}+\mathrm{H}_{2} \mathrm{O}$

(Eq. 8)

$\mathrm{Zn}^{2+}+2 \mathrm{OH} \longrightarrow \mathrm{ZnO}+\mathrm{H}_{2} \mathrm{O}$

(Eq. 9)

$\mathrm{Zn}^{+}+2 \mathrm{OH}^{0} \rightarrow \mathrm{Zn}(\mathrm{OH})_{2}$

$\mathrm{Zn}(\mathrm{OH})_{2} \longrightarrow \mathrm{ZnO}+\mathrm{H}_{2} \mathrm{O}$

(Eq. 11)

$\mathrm{Zn}^{2+}+2 \mathrm{O}_{2}{ }^{0} \rightarrow \mathrm{ZnO}+3 / 2 \mathrm{O}_{2}$

According to Figure 5, azithromycin removal efficiency increased with increase of catalyst concentration up to $1 \mathrm{~g} / \mathrm{L}$ and then remained almost constant. The addition of more amounts of catalyst to the reaction system results in the interactions between catalyst particles, thus, ultrasonic energy cannot reach the catalyst surface, resulting in the less active production of active radicals. This can be explained by the fact that when all of the antibiotic molecules settle on the nanoparticles, adding more amounts of catalyst does not affect the efficiency due to the absence of antibiotic molecules $(41,42)$. Actually, ultrasonic device is used as an energy source to activate catalyst nanoparticles. Due to the high energy levels, nanoparticles tend to accumulate, but ultrasonic waves lead to their dispersion and non-accumulation. When the concentration of the catalyst nanoparticles exceeds a certain limit, ultrasonic energy will not be enough to disperse them, therefore, the removal efficiency remains constant despite the addition of more catalysts (43). These results were consistent with the results of other studies that investigated the effects of various concentrations of $\mathrm{ZnO}$ nanoparticles on the organic pollutants decomposition in AOPs (44). Excessive catalyticity in the sonolysis due to the turbulence occurring in the process, leads to increased darkness in the solution, and consequently its incremental effect will not continue (45).

The formation of hydroxyl radicals may be due to the breakdown of $\mathrm{O}-\mathrm{O}$ bond in $\mathrm{H}_{2} \mathrm{O}_{2}$ by ultrasonic waves $(14,46,47)$. The effect of $\mathrm{H}_{2} \mathrm{O}_{2}$ (the production of most hydroxyl radicals) is defined in the following formulas: $\mathrm{H}_{2} \mathrm{O}+\mathrm{US} \rightarrow \bullet \mathrm{H}+\mathrm{HO} \bullet$

$\mathrm{H}_{2} \mathrm{O}_{2}+\bullet \mathrm{H} \longrightarrow \mathrm{H}_{2} \mathrm{O}+\mathrm{HO} \bullet$

$\mathrm{H}_{2} \mathrm{O}_{2}+\bullet \mathrm{O} \rightarrow \mathrm{HO}_{2}+\mathrm{HO} \bullet$

$\mathrm{H}_{2} \mathrm{O}+\bullet \mathrm{O} \longrightarrow 2 \mathrm{HO} \bullet$

$\mathrm{H}_{2} \mathrm{O}_{2}+\mathrm{US} \longrightarrow 2 \mathrm{HO} \bullet$

The hydrogen formed in reaction 13 reacts with $\mathrm{H}_{2} \mathrm{O}_{2}$ to produce hydroxyl radicals (Eq. 14). On the other hand, the oxygen atoms produced by the dissolution of molecular oxygen in the reaction with $\mathrm{H}_{2} \mathrm{O}_{2}$ (Eq. 15) and water (Eq. 16), generate more radicals. In addition, the sonolysis can directly act as a source of hydroxyl radical production in response to $\mathrm{H}_{2} \mathrm{O}_{2}$ (Eq17) (48). $\mathrm{H}_{2} \mathrm{O}_{2}$ is broken down by ultrasound (sonolysis) into $\mathrm{OH}$, in two following ways $(49,50)$ :

$\bullet \mathrm{H}+\mathrm{H}_{2} \mathrm{O}_{2} \longrightarrow \cdot \mathrm{OH}+\mathrm{H}_{2} \mathrm{O}$

$\mathrm{H}_{2} \mathrm{O}_{2} \longrightarrow 2 \cdot \mathrm{OH}$

In the study on sonochemical degradation of ofloxacin in the presence of $100 \mathrm{mM} \mathrm{H}_{2} \mathrm{O}_{2}$ by Hapeshi et al, degradation efficiency increased from $28 \%$ to $50 \%$ (51). The reason for increase in the degradation efficiency along with the reduction of the initial concentration can be explained by the fact that, under the same conditions, other parameters (catalyst concentration, contact time and $\mathrm{pH}$ ) increased the density of $\mathrm{OH}$-radicals in the lower concentrations, which increased the decomposition of azithromycin released by radicals (51). On the other hand, at higher initial concentration of azithromycin, due to the limited amount of adsorption at the catalyst level, the removal percentage decreases. By increasing the concentration of azithromycin, the probability of a reaction between the pollutant and the reactive species is decreased. In addition, intermediates may be formed during side reactions $(32,52,53)$. Serna-Galvis et al examined the sonochemical degradation of fluoxetine (FLX) with various parameters, including the initial concentration of the pollutant. The results showed that high concentration of FLX leads to an increase in degradation rates, and stated that the amount of $\mathrm{H}_{2} \mathrm{O}_{2}$ accumulation decreased with increasing the concentrations of pollutants. On the other hand, at higher concentration of the pollutant, the FLX molecules 
Table 1. The degradation of pharmaceutical compounds by ultrasonic methods using various catalysts

\begin{tabular}{|c|c|c|c|c|c|}
\hline \multirow{2}{*}{ Pollutant } & \multicolumn{2}{|c|}{ Catalyst } & \multirow{2}{*}{$\begin{array}{l}\text { Time } \\
\text { (min) }\end{array}$} & \multirow{2}{*}{ Removal (\%) } & \multirow{2}{*}{ Reference } \\
\hline & Type & Concentration & & & \\
\hline Amoxicillin & $\mathrm{Co}^{2+}$ & $0.045 \mathrm{mmol} / \mathrm{L}$ & 60 & 98.7 & 32 \\
\hline Levofloxacin & $\mathrm{Ccl}_{4}$ & $0.02 \mathrm{~mL}$ & 35 & 80 & 37 \\
\hline Tetracycline & $\mathrm{Fe}_{3} \mathrm{O}_{4}$ & $1 \mathrm{~g} / \mathrm{L}$ & 90 & 89 & 52 \\
\hline Acetaminophen, Naproxen & $\mathrm{TiO}_{2}$ & - & 30 & AAP 60.1, NPX 72.4 & 25 \\
\hline Fluoxetine & - & - & 60 & 80 & 54 \\
\hline Sulfamethoxazole & Carbon nanotubes & $10 \mathrm{~g} / \mathrm{L}$ & 60 & 88 & 55 \\
\hline Ibuprofen & Carbon nanotubes & $10 \mathrm{~g} / \mathrm{L}$ & 60 & 94 & 55 \\
\hline Ibuprofen & - & - & 30 & 98 & 56 \\
\hline Azithromycin & $\mathrm{ZnO}$ & $1 \mathrm{~g} / \mathrm{L}$ & 15 & 98.4 & Present study \\
\hline
\end{tabular}

are closer to the cavitation bubbles, therefore, the reaction with $\mathrm{OH}^{0}$ is performed (54).

Table 1 shows the degradation of pharmaceutical compounds by ultrasonic methods in the optimum conditions. As shown in Table 1, various catalysts increased the degradation efficiency. However, the use of $\mathrm{ZnO}$ as a catalyst has some advantages including high efficiency, short reaction time, and easy workup.

\section{Conclusion}

In this study, degradation of azithromycin from aqueous sources was investigated by ultrasonic method using $\mathrm{ZnO}$ catalyst. Studies have shown that parameters such as $\mathrm{pH}$, temperature, initial concentration of pollutant, catalyst, and time, affect the degradation process. According to the results, a high percentage of azithromycin removal was obtained in optimal conditions at $\mathrm{pH}=3$, temperature $=40^{\circ} \mathrm{C}$, initial concentration of azithromycin $=20 \mathrm{mg} / \mathrm{L}$ and $\mathrm{ZnO}$ dosage $=1 \mathrm{~g} / \mathrm{L}$ after $15 \mathrm{~min}$. In these conditions, the azithromycin removal was $90.59 \%$. Addition of $\mathrm{H}_{2} \mathrm{O}_{2}$ as an oxidizing agent, significantly increased the removal percentage (98.4\%). Recently, researchers have explored the effective and costeffective methods for wastewater treatment. Therefore, based on the previous studies and the results of the present study, it is concluded that the AOPs are suitable methods for the treatment of wastewaters containing pharmaceuticals.

\section{Acknowledgments}

This study, conducted as a research project (ID:1396/24355) in 2016, was funded by the Research Council of University of Birjand, South Khorasan. Authors genuinely appreciate the authorities of the Research Council and Faculty of Natural Resources and Environment, University of Birjand, for their sincere co-operation.

\section{Ethical issues}

There were no ethical issues in the performance of this study.

\section{Competing interests}

The authors declared no competing interests.

\section{Authors' contributions}

All authors were participated in all stages of this article, like data collection, analysis and interpretation and the manuscript approval.

\section{References}

1. Sayadi MH, Trivedy RK, Pathak RK. Pollution of pharmaceuticals in environment. I Control Pollution 2010; 26(1): 89-94.

2. Gadipelly C, Perez-Gonzalez A, Yadav GD, Ortiz I, Ibanez R, Rathod VK, et al. Pharmaceutical Industry wastewater: review of the technologies for water treatment and reuse. Ind Eng Chem Res 2014; 53(29): 11571-92. doi: 10.1021/ ie $501210 \mathrm{j}$.

3. Lin AY, Lin CF, Chiou JM, Hong PK. O(3) and $\mathrm{O}(3) / \mathrm{H}(2)$ $\mathrm{O}(2)$ treatment of sulfonamide and macrolide antibiotics in wastewater. J Hazard Mater 2009; 171(1-3): 452-8. doi: 10.1016/j.jhazmat.2009.06.031.

4. Grujic S, Vasiljevic T, Lausevic M. Determination of multiple pharmaceutical classes in surface and ground waters by liquid chromatography-ion trap-tandem mass spectrometry. J Chromatogr A 2009; 1216(25): 4989-5000. doi: 10.1016/j.chroma.2009.04.059.

5. Bhandari A,CloseLI,Kim W,HunterRP,KochDE,Surampalli RY. Occurrence of ciprofloxacin, sulfamethoxazole, and azithromycin in municipal wastewater treatment plants. Practice Periodical of Hazardous, Toxic, and Radioactive Waste Management 2008; 12(4): 275-81. doi: 10.1061/ (ASCE) 1090-025X(2008)12:4(275).

6. Bahal N, Nahata MC. The new macrolide antibiotics: azithromycin, clarithromycin, dirithromycin, and roxithromycin. Ann Pharmacother 1992; 26(1): 46-55. doi: $10.1177 / 106002809202600112$.

7. Homem V, Santos L. Degradation and removal methods of antibiotics from aqueous matrices--a review. J Environ Manage 2011; 92(10): 2304-47. doi: 10.1016/j. jenvman.2011.05.023.

8. Rivera-Utrilla J, Sanchez-Polo M, Ferro-Garcia MA, Prados-Joya G, Ocampo-Perez R. Pharmaceuticals as emerging contaminants and their removal from water. A 
review. Chemosphere 2013; 93(7): 1268-87. doi: 10.1016/j. chemosphere.2013.07.059.

9. Sayadi $\mathrm{MH}$, Ahmadpour N. The ultrasonic of drug removal using catalysts from aqueous solutions. Int J Environ Sci Nat Res 2017; 5(4): 555668. doi: 10.19080/ IJESNR.2017.05.555668

10. Baran W,SochackaJ,WardasW.Toxicityandbiodegradability of sulfonamides and products of their photocatalytic degradation in aqueous solutions. Chemosphere 2006; 65(8): 1295-9. doi: 10.1016/j.chemosphere.2006.04.040.

11. Uslu MO, Balcioglu IA. Simultaneous removal of oxytetracycline and sulfamethazine antibacterials from animal waste by chemical oxidation processes. J Agric Food Chem 2009; 57(23): 11284-91. doi: 10.1021/jf902188j.

12. Bremner DH, Burgess AE, Chand R. The chemistry of ultrasonic degradation of organic compounds. Curr Org Chem 2011; 15(2): 168-77. doi: $10.2174 / 138527211793979862$.

13. Abdelsalam ME, Birkin PR. A study investigating the sonoelectrochemical degradation of an organic compound employing Fenton's reagent. Phys Chem Chem Phys 2002; 4(21): 5340-5. doi: 10.1039/B205987H.

14. Pang YL, Abdullah AZ, Bhatia S. Review on sonochemical methods in the presence of catalysts and chemical additives for treatment of organic pollutants in wastewater. Desalination 2011; 277(1-3): 1-14. doi: 10.1016/j. desal.2011.04.049.

15. Hoseini M, Safari GH, Kamani H, Jaafari J, Ghanbarain M, Mahvi AH. Sonocatalytic degradation of tetracycline antibiotic in aqueous solution by sonocatalysis. Toxicol Environ Chem 2013; 95(10): 1680-9. doi: $10.1080 / 02772248.2014 .901328$.

16. Michael I, Rizzo L, McArdell CS, Manaia CM, Merlin C, Schwartz T, et al. Urban wastewater treatment plants as hotspots for the release of antibiotics in the environment: A review. Water Res 2013; 47(3): 957-95. doi: 10.1016/j. watres.2012.11.027.

17. Villaroel E, Silva-Agredo J, Petrier C, Taborda G, TorresPalma RA. Ultrasonic degradation of acetaminophen in water: effect of sonochemical parameters and water matrix. Ultrason Sonochem 2014; 21(5): 1763-9. doi: 10.1016/j. ultsonch.2014.04.002.

18. Lifka J, Ondruschka B, Hofmann J. The use of ultrasound for the degradation of pollutants in water: aquasonolysis - a review. Eng Life Sci 2003; 3(6): 253-62. doi: 10.1002/ elsc. 200390040 .

19. Hartmann J, Bartels P, Mau U, Witter M, Tumpling WV, Hofmann J, et al. Degradation of the drug diclofenac in water by sonolysis in presence of catalysts. Chemosphere 2008; 70(3): 453-61. doi: 10.1016/j.chemosphere.2007.06.063.

20. Hu B, Zhou J, Wu XM. Decoloring methyl orange under sunlight by a photocatalytic membrane reactor based on $\mathrm{ZnO}$ nanoparticles and polypropylene macroporous membrane. Int J Polym Sci 2013; 2013: 451398. doi: $10.1155 / 2013 / 451398$.

21. Wang J, Lv Y, Zhang L, Liu B, Jiang R, Han G, et al. Sonocatalytic degradation of organic dyes and comparison of catalytic activities of $\mathrm{CeO} 2 / \mathrm{TiO} 2, \mathrm{SnO} 2 / \mathrm{TiO} 2$ and $\mathrm{ZrO} 2 / \mathrm{TiO} 2$ composites under ultrasonic irradiation. Ultrason Sonochem 2010; 17(4): 642-8. doi: 10.1016/j. ultsonch.2009.12.016.
22. Elmolla ES, Chaudhuri M. Photocatalytic degradation of amoxicillin, ampicillin and cloxacillin antibiotics in aqueous solution using $\mathrm{UV} / \mathrm{TiO} 2$ and $\mathrm{UV} / \mathrm{H} 2 \mathrm{O} 2 / \mathrm{TiO} 2$ photocatalysis. Desalination 2010; 252(1-3): 46-52. doi: 10.1016/j.desal.2009.11.003.

23. Goel $M$, Hongqiang $H$, Mujumdar AS, Ray MB. Sonochemical decomposition of volatile and non-volatile organic compounds--a comparative study. Water Res 2004; 38(19): 4247-61. doi: 10.1016/j.watres.2004.08.008.

24. De Bel E, Dewulf J, Witte BD, Van Langenhove H, Janssen C. Influence of $\mathrm{pH}$ on the sonolysis of ciprofloxacin: Biodegradability, ecotoxicity and antibiotic activity of its degradation products. Chemosphere 2009; 77(2): 291-5. doi: $\quad 10.1016 /$ j.chemosphere.2009.07.033.

25. Im JK, Yoon J, Her N, Han J, Zoh KD, Yoon Y. Sonocatalytic$\mathrm{TiO} 2$ nanotube, Fenton, and $\mathrm{CCl} 4$ reactions for enhanced oxidation, and their applications to acetaminophen and naproxen degradation. Sep Purif Technol 2015; 141: 1-9. doi: 10.1016/j.seppur.2014.11.021.

26. Mason TJ, Lorimer JP. Sonochemistry in Environmental Protection and Remediation. In: Applied Sonochemistry: Uses of Power Ultrasound in Chemistry and Processing. New York: Wiley; 2003. p. 131-156. doi: 10.1002/352760054X. ch4.

27. Leong T, Ashokkumar M, Kentish S. The fundamentals of power ultrasound-A review. Acoust Aust 2011; 39(2): 5463.

28. Thokchom B, Kim K, Park J, Khim J. Ultrasonically enhanced electrochemical oxidation of ibuprofen. Ultrason Sonochem 2015; 22: 429-36. doi: 10.1016/j. ultsonch.2014.04.019

29. Xu M, Du H, Gu X, Lu S, Qiu Z, Sui Q. Generation and intensity of active oxygen species in thermally activated persulfate systems for the degradation of trichloroethylene. RSC Adv 2014; 4(76): 40511-7. doi: 10.1039/C4RA04942J.

30. Braeutigam P, Franke M, Schneider RJ, Lehmann A, Stolle A, Ondruschka B. Degradation of carbamazepine in environmentally relevant concentrations in water by Hydrodynamic-Acoustic-Cavitation (HAC). Water Res 2012; 46(7): 2469-77. doi: 10.1016/j.watres.2012.02.013.

31. Neis U. The use of power ultrasound for wastewater and biomass treatment. In: Gallego-Juárez JA, Graff KF, eds. Power Ultrasonics: Applications of High-Intensity Ultrasound. Oxford: Woodhead Publishing; 2015: 973-96. doi: $\quad$ 10.1016/B978-1-78242-028-6.00032-6.

32. Su S, Guo W, Yi C, Leng Y, Ma Z. Degradation of amoxicillin in aqueous solution using sulphate radicals under ultrasound irradiation. Ultrason Sonochem 2012; 19(3): 469-74. doi: 10.1016/j.ultsonch.2011.10.005.

33. Bazrafshan E, Mohammadi L, Kord Mostafapour F, Zazouli MA. Adsorption of Methylene blue from aqueous solutions onto low-cost $\mathrm{ZnCl} 2$ treated Pistachio-nut shell ash. Wulfenia 2013; 20(11): 149-63.

34. Meskin PE, Ivanov VK, Barantchikov AE, Churagulov BR, Tretyakov YD. Ultrasonically assisted hydrothermal synthesis of nanocrystalline $\mathrm{ZrO} 2, \mathrm{TiO} 2, \mathrm{NiFe} 2 \mathrm{O} 4$ and

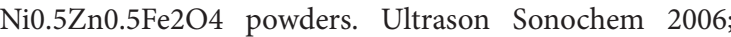
13(1): 47-53. doi: 10.1016/j.ultsonch.2004.12.002.

35. Billik P, Plesch G. Mechanochemical synthesis of nanocrystalline $\mathrm{TiO} 2$ from liquid $\mathrm{TiCl} 4$. Scr Mater 2007; 56(11): 979-82. doi: 10.1016/j.scriptamat.2007.01.048. 
36. Villegas-Guzman P, Silva-Agredo J, Giraldo-Aguirre $\mathrm{AL}$, Florez-Acosta $\mathrm{O}$, Petrier C, Torres-Palma RA. Enhancement and inhibition effects of water matrices during the sonochemical degradation of the antibiotic dicloxacillin. Ultrason Sonochem 2015; 22: 211-9. doi: 10.1016/j.ultsonch.2014.07.006.

37. Guo W, Shi Y, Wang H, Yang H, Zhang G. Intensification of sonochemical degradation of antibiotics levofloxacin using carbon tetrachloride. Ultrason Sonochem 2010; 17(4): 6804. doi: 10.1016/j.ultsonch.2010.01.004.

38. Wang J, Jiang Z, Zhang Z, Xie Y, Wang X, Xing Z, et al. Sonocatalytic degradation of acid red $\mathrm{B}$ and rhodamine $\mathrm{B}$ catalyzed by nano-sized $\mathrm{ZnO}$ powder under ultrasonic irradiation. Ultrason Sonochem 2008; 15(5): 768-74. doi: 10.1016/j.ultsonch.2008.02.002.

39. Kummerer K. Antibiotics in the aquatic environment--a review--part I. Chemosphere 2009; 75(4): 417-34. doi: 10.1016/j.chemosphere.2008.11.086.

40. Gao XD, Li XM, Yu WD, Li L, Peng F, Zhang CY. Microstructure analysis and formation mechanism of $\mathrm{ZnO}$ nanoporous film via the ultrasonic irradiation mediated SILAR method. J Cryst Growth 2006; 291(1): 175-82. doi: 10.1016/j.jcrysgro.2006.02.008.

41. Jia X, Fan H, Zhang F, Qin L. Using sonochemistry for the fabrication of hollow $\mathrm{ZnO}$ microspheres. Ultrason Sonochem 2010; 17(2): 284-7. doi: 10.1016/j. ultsonch.2009.09.010.

42. Jamalluddin NA, Abdullah AZ. Reactive dye degradation by combined $\mathrm{Fe}(\mathrm{III}) / \mathrm{TiO} 2$ catalyst and ultrasonic irradiation: Effect of $\mathrm{Fe}(\mathrm{III})$ loading and calcination temperature. Ultrason Sonochem 2011; 18(2): 669-78. doi: 10.1016/j. ultsonch.2010.09.004.

43. Salehi M, Hashemipour H, Mirzaee M. Experimental study of influencing factors and kinetics in catalytic removal of methylene blue with $\mathrm{TiO} 2$ nanopowder. Am J Environ Eng 2012; 2(1): 1-7. doi: 10.5923/j.ajee.20120201.01.

44. Sanchez-Prado L, Barro R, Garcia-Jares C, Llompart M, Lores M, Petrakis C, et al. Sonochemical degradation of triclosan in water and wastewater. Ultrason Sonochem 2008; 15(5): 689-94. doi: 10.1016/j.ultsonch.2008.01.007.

45. Ertugay N, Acar FN. The degradation of Direct Blue 71 by sono, photo and sonophotocatalytic oxidation in the presence of ZnO nanocatalyst. Appl Surf Sci 2014; 318: 1216. doi: 10.1016/j.apsusc.2014.01.178.

46. Bhavani R, Sivasamy A. Sonocatalytic degradation of malachite green oxalate by a semiconductor metal oxide nanocatalyst. Ecotoxicol Environ Saf 2016; 134(Pt 2): 40311. doi: 10.1016/j.ecoenv.2015.10.029.

47. Voncina DB, Le Marechal AM. Reactive Dye Decolorization Using Combined Ultrasound/H2O2. Dyes Pigm 2003; 59(2): 173-9. doi: 10.1016/S0143-7208(03)00101-3.

48. Petrier C, Torres-Palma R, Combet E, Sarantakos G, Baup S, Pulgarin C. Enhanced sonochemical degradation of bisphenol-A by bicarbonate ions. Ultrason Sonochem 2010; 17(1): 111-5. doi: 10.1016/j.ultsonch.2009.05.010.

49. Suri RPS, Kamrajapuram A, Fu H. Ultrasound destruction of aqueous 2-chlorophenol in presence of silica and peroxide. Environ Eng Sci 2008; 25(10): 1447-54. doi: 10.1089/ees.2007.0145.

50. Ku Y, Tu YH, Ma CM. Effect of hydrogen peroxide on the decomposition of monochlorophenols by sonolysis in aqueous solution. Water Res 2005 39(6): 1093-8. doi: 10.1016/j.watres.2004.11.036.

51. Hapeshi E, Achilleos A, Papaioannou A, Valanidou L, Xekoukoulotakis NP, Mantzavinos D, et al. Sonochemical degradation of ofloxacin in aqueous solutions. Water Sci Technol 2010; 61(12): 3141-6. doi: 10.2166/wst.2010.921.

52. Hou L, Zhang H, Xue X. Ultrasound enhanced heterogeneous activation of peroxydisulfate by magnetite catalyst for the degradation of tetracycline in water. Sep Purif Technol 2012; 84: 147-52. doi: 10.1016/j.seppur.2011.06.023.

53. Worch E. Adsorption technology in water treatment: fundamentals, processes, and modeling. Berlin, Boston: De Gruyter; 2012.

54. Serna-Galvis EA, Silva-Agredo J, Giraldo-Aguirre AL, Torres-Palma RA. Sonochemical degradation of the pharmaceutical fluoxetine: Effect of parameters, organic and inorganic additives and combination with a biological system. Sci Total Environ 2015; 524-525: 354-60. doi: 10.1016/j.scitotenv.2015.04.053.

55. Al-Hamadani YAJ, Chu KH, Flora JRV, Kim DH, Jang M, Sohn J, et al. Sonocatalytical degradation enhancement for ibuprofen and sulfamethoxazole in the presence of glass beads and single-walled carbon nanotubes. Ultrason Sonochem 2016; 32: 440-8. doi: 10.1016/j. ultsonch.2016.03.030.

56. Mendez-Arriaga F, Torres-Palma RA, Petrier C, Esplugas S, Gimenez J, Pulgarin C. Ultrasonic treatment of water contaminated with ibuprofen. Water Res 2008; 42(16): 4243-8. doi: 10.1016/j.watres.2008.05.033. 